\title{
O problema da mudança cultural e o papel do Turismo ou o que podem ensinar os índios sobre economia
}

\section{The problem of cultural change and the role played by tourism or what can teach the Indians about economy}

\author{
Sandro Campos Neves (NEVES, S. C.) ${ }^{*}$
}

RESUMO - Ao longo deste trabalho se procurou revisitar aspectos do campo denominado de Antropologia do Turismo no que se refere à abordagem da mudança cultural. Buscou-se discutir o processo de mudança cultural relacionado ao turismo ressaltando o protagonismo das comunidades locais receptoras. Para tanto foi empreendida uma análise da contribuição à questão prestada pela Antropologia do Turismo e interposta a elas algumas teorias etnológicas da transformação indígena. Espera-se demonstrar, como resultado, o modo como as comunidades locais atuam e podem atuar no turismo de modo a preservar o seu senso de identidade e como, no processo, terminam por modificar o próprio turismo.

Palavras-chave: Turismo; Mudança Cultural; Antropologia do Turismo; Povos Indígenas.

ABSTRACT - Throughout this work was attempted to revisit aspects of the field called Anthropology of Tourism as regards the cultural change approach. We attempted to discuss the process of cultural change related to tourism highlighting the role of local host communities. For that it was undertaken an analysis of the contribution to the question provided by the Anthropology of Tourism and brought them some ethnological theories of indigenous transformation. Is expected to demonstrate, as a result, how local communities can operate and act in the way tourism to preserve its sense of identity and how, in the process, end up modifying the tourism itself.

Key words: Tourism; Cultural Change; Tourism Anthropology; Indigenous People.

\footnotetext{
* Formação: Graduação em Turismo pela Universidade Federal de Juiz de Fora (UFJF), Mestrado em Cultura e Turismo pela Universidade Estadual de Santa Cruz/UFBA (UESC/UFBA) e Doutorado em Antropologia pela Universidade Federal da Bahia (UFBA). Professor Adjunto da Universidade Federal do Paraná (UFPR) no Departamento de Turismo do Setor de Ciências Humanas (DETUR/SCH). Membro do Conselho Científico da Revista Turismo e Sociedade desde outubro de 2013. Endereço físico para correspondência; Universidade Federal do Paraná, Departamento de Turismo. Rua Dr. Faivre, 405, $3^{\circ}$ andar. CEP: 86060-140 - Curitiba - Paraná (Brasil). E-mail: sandrocamposneves@ yahoo.com.br
} 


\section{INTRODUÇÃO}

A questão do turismo em Terras Indígenas é relativamente nova para a realidade brasileira e bastante carente de uma abordagem mais sistemática e ampliada, tendo em vista as múltiplas realidades indígenas. Em sua dissertação de mestrado, Corbari (2015) faz uma revisão da literatura nacional específica, apontando o estado da arte e verificando as diversas insuficiências oriundas do pouco número de estudos e da ausência de legislação específica ${ }^{1}$. De todo modo, como a autora demonstra, parece claro que uma das questões que mais se coloca em jogo na literatura brasileira (e, logo se verá, internacional) é como lidar com a mudança cultural no Turismo em Terras Indígenas. Uma vez que a literatura específica comumente aponta o turismo como importante vetor de mudança cultural nas comunidades receptoras, a literatura sobre o Turismo em T.I’s majoritariamente se debruça sobre os reflexos dessa situação para as sociedades indígenas. Resultante disso há uma ampla bibliografia sobre os impactos socioculturais do turismo que insiste em dar um protagonismo exagerado à atividade no processo de mudança cultural dos destinos turísticos e, especificamente, das comunidades indígenas. Como as conclusões sobre a questão não se apresentam satisfatórias, pretendeu-se a seguir tratar de alguns aspectos carentes de revisão acerca da conclusão, tomada mais ou menos como óbvia, do papel do turismo na mudança cultural em sociedades indígenas.

Para empreender tal discussão lança-se mão da bibliografia sobre turismo em T.I's, bem como da teoria do turismo acerca da mudança cultural e o papel da atividade. Contudo, pretendeu-se, sobretudo, revisar algumas discussões à luz da teoria que se está chamando aqui, de forma bastante superficial, de etnologia da transformação indígena. Com esse título se faz referência a abordagens que vão desde Viveiros de Castro (2002) a Albert e Ramos (2002) sobre o papel das sociedades indígenas no seu próprio processo de transformação. Tais abordagens, definidas por Viveiros de Castro (1999)

\footnotetext{
${ }^{1}$ Em 2015 foi aprovada, após um processo de consulta às comunidades indígenas realizado pela FUNAI, a instrução normativa que regulamenta o turismo em Terras Indígenas no Brasil. Em que pese seu aspecto meramente normativo e a recusa em lidar com os problemas mais sérios envolvidos, afinal tem-se alguma legislação a respeito a partir da Instrução Normativa n. 3 de Junho de 2015. Até então, a legislação existente previa apenas o ingresso em Terras Indígenas para fins de pesquisa científica a partir da Instrução Normativa n. 1 / PRES /1995.
} 
como aquelas que tomam as sociedades indígenas em si mesmas ${ }^{2}$ como objeto, buscam tratar do ponto de vista indígena sobre a mudança cultural (entre outros problemas diversos). Surgem, portanto, como abordagens que ao invés de tratar as sociedades indígenas meramente como objeto de ação da colonização pretérita e presente, abordaas como sujeitos de sua própria transformação, atuando de forma inventiva sobre as pressões e demandas diversas de mudança impostas pela sociedade envolvente.

Serão feitos alguns apontamentos sobre o tema tendo como pano de fundo a experiência etnográfica empreendida entre os índios Pataxó da aldeia de Coroa Vermelha, localizada no município de Santa Cruz Cabrália, no estado da Bahia (Brasil), vizinho menos célebre do município de Porto Seguro. Embora se refira à experiência empírica, o objetivo deste artigo de opinião é eminentemente de uma discussão teórica e o material de campo serve como ilustração e apoio de alguns argumentos sugeridos.

\section{A ABORDAGEM dA MUDANÇA CULTURAL NO CAMPO TEÓRICO DO TURISMO, O PROTAGONISMO DA ANTROPOLOGIA DO TURISMO}

No que se refere aos estudos do processo de mudança cultural das sociedades receptoras, no campo teórico do turismo, verifica-se a clara predominância da perspectiva da Antropologia do Turismo. O campo assim denominado compreende predominante, mas não exclusivamente, pesquisas etnográficas - e suas consequências etnológicas - empreendidas por antropólogos que se aproximaram do campo teórico do turismo. Majoritariamente tal aproximação se deu nos limites de interesses teóricos e empíricos compartilhados. Tal abordagem estabeleceu um posicionamento muito crítico acerca do impacto do turismo no processo de mudança cultural nas sociedades receptoras.

Seria possível começar a descrição a partir de duas visões sobre o processo de mudança cultural desenvolvidas no interior do campo da Antropologia do Turismo. Emergem ao menos duas abordagens críticas; a primeira baseia-se na teoria da

\footnotetext{
${ }^{2} \mathrm{O}$ autor opõe tal abordagem etnológica a outra que toma as sociedades indígenas como um objeto construído em relação à sociedade nacional. Tal abordagem, segundo o autor, pecaria, sobretudo, por dar às sociedades indígenas uma atenção condicional, tomando-as majoritariamente como objetos da ação do Estado Brasileiro e analisando as circunstâncias e consequências da ação governamental, terminando por definir os índios a partir de sua interação com a sociedade brasileira, no caso analisado.
} 
aculturação e suas decorrências e a outra no pressuposto do que se chama de uma mercantilização da cultura.

Há relativo consenso, para várias escolas da antropologia, que o primeiro trabalho no campo da Antropologia do Turismo tenha sido o de Nuñez em 1963. No trabalho a relação entre turistas e locais é abordada a partir da perspectiva da aculturação. Desde esse ponto de vista, as modificações na cultura são resultantes da capacidade de resistência da cultura local, de um lado, e da intensidade da pressão ocasionada pelo turismo, de outro. O trabalho de Nuñez (1963) poderia ser relacionado à tradição da antropologia da aculturação que se origina em Herskovits (1938) e se desenvolve consideravelmente em Bastide (1960). Para o que interessa a esse trabalho se poderia dizer que a teoria aparece, no campo da Antropologia do Turismo e no estudo da mudança cultural, como a afirmação da existência de um processo, quase sempre unívoco e teleológico de dominação de uma cultura por outra. Na linha desta teoria encontra-se, no campo da Antropologia do Turismo, diversos desdobramentos que maximizam as pressões do turismo como fatores de modificação da cultura local (BOORSTIN, 1992; GRABURN, 1980; MACCANNELL, 1976; NASH, 1977).

Em 1974 Erik Cohen, a partir de uma abordagem sociológica, enfatiza a relevância do turismo como objeto de investigação. O trabalho de Cohen é marcado por uma abordagem do turismo que enfatiza o aspecto da mercantilização de determinadas relações, tais como as de hospitalidade, no contexto das localidades em que ocorre. É, sobretudo, nesse ponto que o trabalho suscita um debate que se desenvolverá longamente na Antropologia do Turismo, a respeito das relações de hospitalidade e questões como a de sua autenticidade, espontaneidade e as consequências culturais de sua mercantilização (Cohen, 1988). Neste caso, Cohen se encontra articulando conceitos instituídos desde Mauss (1974 [1923-4]) a respeito da hospitalidade e se apropriando dos desdobramentos a eles dados por Arnold Van Gennep (2011 [1909]) e Victor Turner (1974 [1969]). Em sua abordagem, contudo, Cohen analisa contextos inexplorados pelos antecessores e se envolve em todos os riscos pertinentes a tal empreitada.

De modo geral, com relação à questão da mudança cultural, os antropólogos foram extremamente críticos à influência e ao papel do turismo. Desenvolveu-se uma tendência a ver no turismo a razão de ser de uma série de conflitos e problemas das 
sociedades receptoras, que atualmente tenderam a ser abordados tomando em conta seu grau ampliado de complexidade. A partir de uma visão semelhante se pode enquadrar também a coletânea clássica organizada por Valene Smith (1977) "Hosts and Guests". $\mathrm{Na}$ análise dos diversos trabalhos que a compõem se pode visualizar sempre uma perspectiva mais crítica ao turismo.

Em outras abordagens se delineia maior capacidade de relativizar, à luz de contribuições de autores como Sahlins (1972), a visão do turismo como maior influência da mudança cultural. Para Sahlins (1993), a modificação de uma cultura pela outra é sempre uma via de mão dupla e as influência e modificações podem se dar nos dois sentidos da relação. Sahlins aprofunda a questão demonstrando ser a mudança um processo complexo, sujeito à resistência, extremamente criativa, articulada pelas culturas locais. Autores como Steiner e Reisiger (2005) e Cole (2006), na perspectiva aberta por Sahlins (1993), constituíram abordagens que buscavam superar tanto a perspectiva da colonização/dominação total de uma cultura pela outra, quanto a perspectiva segundo a qual os interesses comerciais se dão sempre em prejuízo - e sem reação - das culturas locais. É desses desenvolvimentos mais recentes que se precisa partir para realizar a abordagem da mudança cultural que se gostaria de desenvolver a seguir. Contudo, resta importante recorrer a um contexto teórico pouco explorado pelos autores do campo da Antropologia do Turismo para completar a análise que se deseja desenvolver.

\section{A ETNOLOGIA DA TRANSFORMAÇÃO INDÍGENA}

A essas perspectivas críticas que estabelecem o protagonismo do turismo, e por consequência da colonização, nos processos de transformação indígena busca-se opor o que se está chamando de etnologia da transformação indígena. Observada ao longo de diversas obras de autores como Eduardo Viveiros de Castro (2002), Bruce Albert e Alcida Ramos (2002) entre outros, tal teoria propõe a ideia, controvertida para o entendimento do senso comum a respeito de índios, que as diversas populações 
indígenas ao longo de seus vários processos de interação com os brancos ${ }^{3}$, e nos marcos de suas várias diferenças entre si, estabeleceram diversos processos de 'pacificação dos brancos' e seu mundo. O termo pacificação é usado de forma alusiva ao termo utilizado pelos colonizadores no inicio de seus contatos com as populações indígenas, quando o objetivo de portugueses e neobrasileiros era o de pacificar os 'índios brabos'. Sob o amparo de tal terminologia que alude à paz (e, portanto, a objetivos tidos como civilizatórios e benfazejos) se encontram inúmeros tipos de procedimentos de dominação, que começam com o que se considerou logro nas trocas comerciais e terminam com a tortura e assassínio dos povos indígenas, perpetrados livremente ao longo de toda a história de sua relação com os brancos.

O que os autores propõem com a ideia de pacificação do branco, ou etnologia da transformação, é a suposição, que agora pode ser percebida como lógica e óbvia, de que os índios também realizaram seus experimentos de apreensão do que seriam aqueles seres com os quais passaram a lidar a partir do século XVI no Brasil. Tais experimentos vão desde os relatos de práticas de afogamento dos brancos para 'verificar se eram gente' e, portanto, podiam morrer (cognata da crença, entre os brancos, que os índios não tinham alma, que justificou massivamente seu assassínio na tentativa de conversão a todo preço), até práticas mais contemporâneas de apreensão e ressignificação de objetos e categorias dos brancos à luz da cosmologia indígena ${ }^{4}$. Em que pese a fascinação que os primeiros exemplos possam oferecer, serão observados com mais atenção os segundos, entre os quais se situa o processo de apreensão e transformação do turismo pelos índios. O raciocínio, que após descoberto e descrito passa a parecer óbvio (como é comum nas boas ideias), de que os índios, afinal, são protagonistas de sua própria experiência no mundo, antes de apenas sublevados pelo evento da colonização, pode ser transposto para o entendimento de como eles se relacionam com o turismo.

\footnotetext{
${ }^{3}$ Sempre quando se fizer referência "aos brancos" é preciso que se tenha em conta que o que se deseja abreviar com a expressão é o conjunto de outros com os quais os índios se relacionam, tendo nenhuma relação com a cor de sua pele. Tal termo é o comumente utilizado, pelos próprios índios, para se referir às outras sociedades (comunidades/grupos) não indígenas, com os quais interagem.

${ }^{4}$ Sugere-se fortemente a leitura integral da obra "Pacificando o Branco" de Albert e Ramos (2002) e "O Nativo Relativo" de Viveiros de Castro (2002) para uma efetiva compreensão do potencial inovador destas ideias.
} 


\section{A MUDANÇA CULTURAL E A TRANSFORMAÇÃO DO TURISMO PELOS ÍNDIOS}

A capacidade indígena de rearticular a influência dos brancos em diversos aspectos e ressignificar seus objetos pode ser aplicada à leitura de como organizam a atividade turística e a compreendem no contexto atual. A teoria do turismo tendeu, durante boa parte de sua existência, a compreender a atividade como um modelo préfabricado e estanque a ser simplesmente implantado em diversos destinos e localidades à luz de um receituário sobre 'planejamento correto e responsável' que escamoteava um conjunto de práticas de mercado extraordinariamente favoráveis aos seus propositores. Assim que se veiculou, em boa parte da história da teoria do turismo, que o planejamento e implantação da atividade seria apenas a sucessão de passos mecânicos obedecendo a um modelo teoricamente articulado e reconhecido como válido. Essa, aliás, não é uma exclusividade do turismo, boa parte de toda a história da teoria da administração e gestão pode ser assim lida, como a aplicação pura e simples e ad nauseum de um conjunto de passos inquestionáveis (até que vem sendo finalmente questionados).

É à contraluz deste tipo de entendimento que se deseja, afinal, discutir os processos de mudança cultural no turismo a partir da experiência indígena. Visto como conjunto de passos a ser seguidos de maneira sempre igual, tal qual um processo industrial, o planejamento terminaria irrefreavelmente resultando sempre em um conjunto pré-estabelecido e quase imutável de impactos sociais, culturais, ambientais e econômicos. Contudo, a experiência empírica tem demonstrado de formas cada vez mais inquestionáveis que, tanto o conjunto de passos, quanto seus resultados, os impactos, podem ser imensamente diferentes nos diversos lugares do mundo. Ainda assim, talvez por necessidade de 'compreensão lógica ocidental' e 'organização do conhecimento' pouco se tem questionado efetivamente o poder explicativo dos 'manuais de planejamento e administração'.

É a partir daí que se sugere haver algo a apreender com a experiência turística indígena ou há ao menos que se interrogar o que podem ensinar os índios sobre economia. O caso Pataxó colabora para o entendimento a respeito, por exemplo, e para começar, dos tais passos a ser seguidos para o planejamento da atividade turística. Se é 
possível, como se postula que seja, pensar a experiência Pataxó com o turismo como bem sucedida, seria preciso questionar fortemente a ideia que se faz de planejamento como conjunto de passos que partem de um inventário para chegar aos meios de comercialização e difusão de um produto no mercado, numa ordem teleológica. Os Pataxó, que atuam no turismo na região de Santa Cruz Cabrália, vizinha de Porto Seguro, desde os anos 1970, desde sempre dispensaram os bem acabados conhecimentos dos brancos a respeito do planejamento da atividade. Não que tenham desprezado completamente, em qualquer momento, o conhecimento acadêmico ou a relação com os brancos, mas que sempre prescindiram desta lógica de 'implantação' da atividade e viram nesta 'tecnologia' de planejamento um empecilho constante e insistente a perturbar seu processo de apreensão do turismo.

Passaram os índios por diversos momentos que poderiam parecer assemelhados ao modelo teórico ocidental, por assim dizer, de planejamento e seguiram lógicas de mercado que, em muitos casos, podem passar por assemelhadas às dos brancos. É aí que se acredita residir o maior logro para os brancos que costumam fazer pouco da capacidade indígena de compreensão de sua lógica e reinvenção de seus termos. Muitas vezes, cegos pela incapacidade de lhes reconhecer o protagonismo, deixa-se passar por mesmo aquilo que é efetivamente outro. Por exemplo, o modo como o artesanato Pataxó foi transformado em diversas iniciativas de 'colaboração' de órgãos de auxílio empresarial como o Serviço Brasileiro de Apoio às Micro e Pequenas Empresas (SEBRAE), tendeu a ser visto como, por um lado, etapa do processo de colonização, ou, por outro, como capitulação indígena. O SEBRAE, por exemplo, teve uma participação significativa na padronização da produção do artesanato indígena. Para os homens de negócio do órgão parecia que padronizar o artesanato favoreceria aos índios no sentido de tornar sua produção em algo de fácil reconhecimento para os turistas e como elemento equalizador da qualidade, de forma a garantir a experiência e manutenção de seu consumo. A muitos investigadores causou espécie a forma como os Pataxó cederam facilmente aos intentos padronizadores de seu artesanato. Contudo, poucos tiveram a 'inventividade' de interrogar aos índios as razões de sua franca aceitação da padronização imposta ao artesanato, inclusive, tomando por óbvia sua ingenuidade ou ignorância a respeito dos processos relacionados ao negócio. Tendeu-se também a 
acusar fortemente os órgãos que colaboraram na padronização do artesanato de impor novas e constantes colonizações aos índios.

Contudo, ao interrogar mais profundamente a questão da padronização do artesanato (e, portanto, mudança cultural) entre os Pataxó encontra-se uma conclusão, que nada tem de inovadora pois quem primeiro chega a ela são os próprios índios, que pode parecer assombrosa para os teóricos da mudança cultural. Os Pataxó aceitaram mais do que passiva, mas colaborativamente, a padronização do seu artesanato, não por acreditar que isso lhes oferecia vantagem ou equalização competitiva no mercado. A padronização foi aceita pelos índios como parte de uma estratégia de construção do que os antropólogos costumam chamar de fronteira étnica (BARHT, 1998). Como Barth (2002) demonstra, em um grupo étnico, os conhecimentos a respeito da cultura não são, obviamente, homogeneamente distribuídos. Há especialistas em determinadas questões como os xamãs, curandeiros, líderes políticos, grandes artistas e etc. No entanto, uma estratégia comum de fortalecimento da fronteira étnica diante da convivência intercultural é, justamente, fazer parecer ao outro que o conhecimento é homogeneamente distribuído. A estratégia é empregada, pois isso tenderia a ser compreendido pelos 'de fora' (como logo o perceberam os grupos étnicos) como um elemento 'comprobatório' da distintividade étnica da comunidade, de sua singularidade cultural e da preservação de sua tradição, todos esses aspectos utilizados pelos brancos, ocidentais (ou seja lá qual palavra se queira utilizar para se referir à sociedade ocidental, que se vem chamando de dos brancos) para 'aferir' a etnicidade de uma comunidade. Não foi por outra razão que, em determinado momento da história do SPI (Serviço de Proteção ao Índio) se fazia verificações, para reconhecer comunidades indígenas, do nível de conhecimento e difusão do idioma próprio (seria interessante perceber, como analogia comparativa, por exemplo, o quanto o nível de conhecimento e difusão do português é variado na sociedade brasileira. Seria-se menos brasileiros em função disso?).

Assim, ao aceitar a padronização do artesanato por 'razões mercadológicas' os Pataxó trataram de urdir uma estratégia sofisticada de passar por mesmo aquilo que é, de fato, outro. Ou seja, aparentando adotar um procedimento para atender a anseios de padronização mercadológica, os Pataxó instituíram um modo de comunicar aos 'de fora' aquilo que repetem insistentemente aos seus consumidores em suas lojas de artesanato, 
que "todos os índios Pataxó fazem artesanato do mesmo jeito". Obviamente que esta é uma afirmação perfeitamente ilógica e imprecisa (ou inverídica, dependendo da astúcia do interlocutor). Está claro que existem especialistas no artesanato, produtores que sabem fazer, com diferentes materiais, de diversas formas, artigos mais bem acabados, esteticamente mais atraentes, mais duráveis ou com diversas outras propriedades distintivas. Entretanto, é preferível abrir mão de comunicar e visibilizar essa diferença em favor de uma estratégia que ao supor a equalização de difusão do conhecimento transmite a ideia de ser aquela uma tradição preservada, objeto de fetiche dos turistas, ademais. Assim, pode ser considerado até certo ponto um resultado fortuito que, ao final, o que os Pataxó entendiam como uma estratégia política - que ressaltava a distintividade étnica e, portanto, colaborava para garantir o reconhecimento e consequente acesso ao regime de direitos assegurados como originários na constituição - termina sendo também um elemento de seu sucesso comercial. O fetiche dos turistas pelo artesanato tradicional que encontram convenientemente padronizado terminou sendo o Cavalo de Tróia econômico e político dos Pataxó.

\section{CONSIDERAÇÕES FINAIS}

Poderia seguir relatando diversas formas através das quais os Pataxó, se utilizando da imitação de mecanismos como guias de turismo indígenas, agência Pataxó de turismo e outros objetos tidos como próprios da atividade turística e sua sistemática de planejamento e gestão, compuseram importantes estratégias de articulação de hierarquias, manutenção de tradições e diversos outros dispositivos que lhes eram úteis por razões intrínsecas à sua cosmologia. Contudo, o objetivo aqui é propor a revisão da aceitação pura e simples de que as comunidades receptoras do turismo - as indígenas especificamente para o material empírico de que se dispõe - ao aceitar os padrões de 'implantação' da atividade (tenham sido elas consultadas ou não a respeito) estejam apenas sofrendo os efeitos da colonização. Procura-se advogar aqui sua capacidade de transformar os conhecimentos e objetos dos brancos, o que passa obviamente por sua correta compreensão, para servir aos seus próprios objetivos, antes do que se adequar aos de outros. 
Tal proposição, se aceita, exige repensar a questão da mudança cultural, uma vez que desloca as comunidades receptoras de fluxo turístico do papel de eternas vítimas da colonização e as recoloca no lugar, que em sua própria visão sempre tiveram, de protagonistas de seu destino e seres humanos capazes de ler e rearticular a influência externa a partir de suas próprias necessidades e interesses. ${ }^{5}$ Tal capacidade, quando aplicada à discussão da mudança cultural permite entrever um papel mais ativo das sociedades indígenas diante da influência dos brancos.

Espera-se, assim, haver colaborado para sugerir a revisão deste paradigma, que implica em uma revisão do modo como se compreende não apenas a sistemática de implantação do turismo e as consequências que pode ter para as diversas comunidades, mas todo o processo de imposição de conceitos e categorias que são assinaladas como típicas do capitalismo e da colonização. Sugere-se, aqui, a possibilidade de extrapolar esse raciocínio, cujos limites só foi possível testar e só se pode advogar no contexto de uma comunidade indígena, para as diversas comunidades receptoras de fluxos turísticos. E se arriscar-se imaginar que as comunidades que se chama de vítimas do colonialismo têm um papel a jogar no processo de assimilação dos conteúdos da tal colonização? E se esse papel for de um protagonismo muito maior do que a arrogância cultural dos brancos jamais pudesse ter imaginado? Então se pode chegar à conclusão de que, afinal, tem os índios algo a ensinar a respeito da economia.

\section{REFERÊNCIAS}

ALBERT, B.; RAMOS A. R. (orgs.). Pacificando o Branco: Cosmologias do Contato no Norte-amazônico. São Paulo: Ed. UNESP; Imprensa Oficial do Estado, 2002.

BARTH, F. An Anthropology of Knowledge In: Current Anthropology, The Weener - Gren Foundation for Anthropological Research, v. 43, n. 1, February, 2002.

BARTH, F. Grupos Étnicos e suas fronteiras. In: POUTIGNAT, P.; STREIFFFENARDT, J.(Org.) Teorias da etnicidade. Seguido de grupos étnicos e suas fronteiras de Fredrik Barth, Tradução de Elcio Fernandes. São Paulo: UNESP, 1998.

\footnotetext{
${ }^{5}$ Para uma ampla exposição do raciocínio apresentado, além das obras etnológicas já sugeridas, sugerese, correndo o risco do cabotinismo, a leitura da tese de doutorado "A Apropriação Indígena do Turismo: Os Pataxó de Coroa Vermelha e a Expressão da Tradição”.
} 
BASTIDE, R. Les Religions Africaines au Brésil. Paris, PUF, 1960.

BOORSTIN, D. J. The image: a guide to pseudo-events in America. New York: Vintage Books, 1992.

COHEN, E. Who is a tourist? A conceptual clarification. Sociological Review, n. 22, 1974 , p. 527-555.

COHEN, E. Authenticity and commoditization in tourism. Annals of Tourism Research, 15 (3), 1988, p. 371-386.

COLE, S. Beyond Authenticity and Comodification Annals of Tourism Research, 34 (4), 2007, p. 943-960.

CORBARI, S. D. O Turismo Envolvendo Comunidades Indígenas em Teses e Dissertações: Retrato das Relações e dos Impactos Socioculturais. Dissertação de Mestrado. Programa de Pós-Graduação em Turismo, UFPR, 2015.

GENNEP, A. V. [1909] Os ritos de passagem. 2. ed., Trad. Mariano Ferreira. Petrópolis: Vozes, 2011.

GRABURN, N. Tourism: The sacred journey. In: Hosts and guests: The anthropology of tourism. V. Smith, ed. Philadelphia: University of Pennsylvania Press, 1977.

GRABURN, N. Teaching the anthropology of tourism. International Social Science Journal, 32(1), 1980, p: 56-68.

HERSKOVITS, M. Acculturation: The Study of Cultural Contact. New York, J.J. Augustin Publisher, 1938.

MACCANNELL, D. The tourist: A new theory of the leisure class. University of California Press, 1976.

MAUSS, M. 1974 [1923-24]. Ensaio sobre a dádiva. Forma e razão da troca nas sociedades arcaicas. In: Sociologia e Antropologia, v. II. São Paulo: Edusp, 1974.

NASH, D. Tourism as a form of imperialism. In Hosts and guests: The anthropology of tourism. 2nd Ed. V. Smith, ed. Philadelphia: University of Pennsylvania Press, 1977.

NUÑEZ, T. Tourism, tradition, and acculturation: Weekendismo in a Mexican village. Ethnology, 2.3 1963, p. 347-352.

SAHLINS, M. Stone age economics. Chicago: Aldine, 1972.

Adeus aos tristes tropos: a etnografia no contexto da moderna história mundial. In: SAHLINS, Marshall. Cultura na prática. Rio de Janeiro: Editora UFRJ, 2004. p. 503-534. 
SMITH, V. L. (Org.) Hosts and Guests. The Anthropology of Tourism. Philadelphia: University of Pennsylvania Press, 1977.

STEINER, C. J.; REISINGER, Y. Reconceptualizing Object Authenticity. In: Annals of Tourism Research, v. 33, n. 1, p. 65-86, 2006.

TURNER, V. O Processo Ritual. Petrópolis: Vozes, 1974.

VIVEIROS DE CASTRO, E. O Nativo Relativo. Mana, v. 8, n. 1, Rio de Janeiro, Abr. 2002.

Etnologia brasileira. In: MICELI, S. (Org.). O que ler na ciência social brasileira (1970-1995). São Paulo: Sumaré/ANPOCS (v. 1, Antropologia), 1999. 